Original Research Article

\title{
Treatment adherence and factors contributing to non adherence among type 2 diabetes mellitus patients in a tertiary care hospital: a cross sectional study
}

\author{
Kavitha S. ${ }^{*}$, Nalini G. K. ${ }^{1}$, Suresh R. M. ${ }^{2}$, Sahana G. N. ${ }^{1}$, Deepak P. ${ }^{1}$, Jayashree V. Nagaral ${ }^{1}$
}

${ }^{1}$ Department of Pharmacology, Hassan Institute of Medical Science, Hassan, India ${ }^{2}$ Department of Medicine, Hassan Institute of Medical Science, Hassan, India

Received: 30 December 2016

Accepted: 31 January 2017

*Correspondence to:

Dr. Kavitha S.,

Email:

natrajrkesvar@gmail.com

Copyright: () the author(s), publisher and licensee Medip Academy. This is an openaccess article distributed under the terms of the Creative Commons Attribution NonCommercial License, which permits unrestricted noncommercial use, distribution, and reproduction in any medium, provided the original work is properly cited.

\begin{abstract}
Background: Diabetes mellitus (DM) is the most common endocrine disorder and major global public health problem. Lack of adherence to antidiabetic medication has lead to suboptimal blood sugar control, treatment failure, accelerated development of complications and increased mortality, thus medication adherence plays an important role in disease control. Hence present study was taken to evaluate the treatment adherence and factors affecting non adherence among Type 2 diabetes mellitus patients.

Methods: A cross sectional study carried out by Department of Pharmacology and Medicine, Hassan Institute of Medical Sciences, Hassan. Total 150 patients of type 2 diabetes were recruited after taking their informed consent. Adherence to treatment and factors associated with non adherence has been assessed during a personal interview with each patient using standardized questionnaire.

Results: Adherence levels were $28 \%, 42 \%$ and $30 \%$ for high, medium and poor adherence respectively. The overall prevalence of non adherence among respondents was $30 \%$. Among them $77.77 \%$ were males, $44.44 \%$ belonged to age group of $41-60$ years, $40 \%$ illiterate, $60 \%$ employed, $51.11 \%$ of patients with smoking and alcoholic habits were not adherent to anti diabetic treatment. Other reasons contributing to non-adherence to treatment were forget fullness (86.66 \%), inadequate knowledge about side effects (80\%), unhappy clinical visits $(71.11 \%)$ and lack of assistance $(48.88 \%)$.

Conclusions: Results showed that patients in the area of study were moderately adherent to anti-diabetic medications. This emphasizes the need for constant motivation and education at frequent intervals to ensure better adherence.
\end{abstract}

Keywords: Factors, Medication adherence, Type 2 Diabetes mellitus

\section{INTRODUCTION}

"Diabetes mellitus is a metabolic disorder of multiple etiology characterized by chronic hyperglycemia with disturbances of carbohydrate, fat and protein metabolism resulting from defects in insulin secretion, insulin action, or both". ${ }^{1}$

As per the World Health Organization, there were around 31.7 million individuals in India affected by diabetes during the year 2000, which was expected to rise to 79.4 million by the year $2030 .^{2}$ It is a challenging disease and successful management includes frequent self monitoring of blood glucose, dietary modifications, exercise, and administration of medication on schedule. ${ }^{3}$ Despite the benefits of therapy, studies have shown that recommended glycemic levels are achieved in less than $50 \%$ of patients, which may be associated with decreased adherence to therapies. ${ }^{4}$ Hence adherence to prescribed medication plays an important role.

Adherence to medication as used in chronic disorders is defined as proportion of medication prescribed by the health care provider actually taken by the patient during 
specified period of time..$^{5}$ Adherence to diabetes treatment not only include adherence to medication, dietary changes and life style modification but also depends on patient related factors which include age, sex, education, income, socioeconomic status, healthcare system related factors such as availability and ease of accessibility of the physician, long waiting time, unhappy clinic visits or therapy-related such as route of administration, duration of treatment, complexity of treatment and the side effects of the medicines. ${ }^{6-8}$

Lack of adherence to treatment in type 2 diabetes patients has resulted in poor glycemic control, which can lead to development of complications like neuropathy, nephropathy, retinopathy, cardiovascular and cerebrovascular diseases. ${ }^{9,10}$ Various potential risk factors of non adherence to diabetic medication have been identified in many studies. However evaluation of adherence on a regular basis is essential due to changes in cultural practices and life style. In addition, the introduction of new medicine in the market with their varied dosing schedule, efficacy and adverse drug profile may also alter adherence. ${ }^{11}$ Therefore this study was taken which would benefit our physicians in making decisions and to achieve glycemic control in diabetes mellitus patients.

\section{Objectives}

1. To study the treatment adherence

2. Factors affecting non adherence among Type 2 diabetes mellitus (DM) patients in Sri Chamarajendra Hospital, HIMS, Hassan.

\section{METHODS}

This cross sectional study was carried out after taking clearance from Institutional ethics committee. Total 150 type 2 diabetes patients attending Medicine OPD, Sri Chamarajendra Hospital, HIMS, Hassan fulfilling inclusion criteria during period (August-September 2015) were recruited in the study.

\section{Inclusion criteria}

- Known Type 2 DM patients of either gender, aged $>18 y$ rs on antidiabetic drugs for at least 3 months.

- Patients with associated co-morbid illness like Hypertension, $\mathrm{CHF}$ and dyslipidaemia.

\section{Exclusion criteria}

- Patients with gestational diabetes and any psychiatric illness with or without anti diabetic medication were excluded from this study.

\section{Data collection}

For data collection and documentation, Patient profile form which included information on patients demographic details, presenting complaints, social habits, past medical/medication history, current medications details was collected after taking informed consent.

Two separate questionnaires were designed to assess treatment adherence and factors affecting non adherence.

An eight item Morisky Medication adherence questionnaire (Table 1) was used to assess medication adherence. $^{12}$

Patients responded yes or no to each of the questions asked.

Based on the scores obtained:

- 0 - considered high adherence

- 1 or 2 - medium adherence

- $\quad>2$ - low adherence

Table 1: Eight item modified Morisky adherence scale.

\begin{tabular}{|ll|}
\hline Sl.no. & Questionnaire \\
\hline 1 & $\begin{array}{l}\text { Do you sometimes forget to take your } \\
\text { medicine }\end{array}$ \\
\hline 2 & $\begin{array}{l}\text { Thinking over the past } 2 \text { weeks, were there any } \\
\text { days when you did not take your medicine }\end{array}$ \\
\hline 3 & $\begin{array}{l}\text { Have you ever cut back or stopped taking your } \\
\text { medicine without telling your doctor because } \\
\text { you felt worse when you took it }\end{array}$ \\
\hline 5 & $\begin{array}{l}\text { When you travel or leave home, do you } \\
\text { sometimes forget to bring along your } \\
\text { medicines }\end{array}$ \\
\hline 6 & $\begin{array}{l}\text { Did you take all your medicines yesterday you feel like your symptoms are under } \\
\text { control, do you sometimes stop taking your } \\
\text { medicines }\end{array}$ \\
\hline 7 & $\begin{array}{l}\text { Taking medicine every day is a real } \\
\text { inconvienience for some people, Do you ever } \\
\text { feel hassled about sticking to your treatment } \\
\text { plan and by choosing one of the options for the } \\
\text { question }\end{array}$ \\
\hline 8 & $\begin{array}{l}\text { How often do you have difficulty remembering } \\
\text { to take all your medicines, } \\
\text { (A) Never/rarely, (B) Once in a while, (C) } \\
\text { Sometimes, (D) Usually, (E) All the time }\end{array}$ \\
\hline
\end{tabular}

Another questionnaire was designed to collect information on probable factors affecting non- adherence (Table 2). ${ }^{13}$

In this study, medium and high adherence were considered as adherent and low adherence as nonadherent group for statistical purpose. Only those participants who had completed both the questionnaires were considered for statistical analysis. 
Table 2: Questionnaire to evaluate the factors associated with non-adherance.

\begin{tabular}{|c|c|}
\hline $\begin{array}{l}\text { Patient- } \\
\text { centered } \\
\text { factors }\end{array}$ & $\begin{array}{l}\text { Patient knowledge } \\
\text { Tobacco smoking or alcohol intake } \\
\text { Forgetfulness - Busy } \\
\text { schedule/Travel Lack of assisstance }\end{array}$ \\
\hline $\begin{array}{l}\text { Therapy- } \\
\text { related } \\
\text { factors }\end{array}$ & $\begin{array}{l}\text { Route of administration } \\
\text { Treatment complexity Duration of the } \\
\text { treatment period } \\
\text { Medication side effects Taste of the } \\
\text { medication }\end{array}$ \\
\hline $\begin{array}{l}\text { Healthcare } \\
\text { system } \\
\text { factors }\end{array}$ & $\begin{array}{l}\text { Lack of accessibility } \\
\text { Long waiting time } \\
\text { Unhappy clinic visits }\end{array}$ \\
\hline $\begin{array}{l}\text { Economic } \\
\text { factors }\end{array}$ & Cost and Income \\
\hline
\end{tabular}

\section{Statistical analysis}

Data collected was entered using Microsoft Excel and responses were expressed in percentage. Chi-square test was applied to assess the association of factors with adherence using Graph-pad, statistical software.

\section{RESULTS}

A total of 150 patients participated in this study and completed the questionnaire, out of which $52 \%$ were males and $48 \%$ were females. Most patients belonged to the elderly age group $>60$ years $(50 \%)$ followed by middle age group 41-60 years $(42 \%)$. $48 \%$ patients were illiterate and the occupation section of the respondent showed that $64 \%$ patients were unemployed and majority of patients $(88 \%)$ were from rural background. Sociodemographic details are summarized in Table 4.

Table 3: Eight item Morisky adherence scale.

\begin{tabular}{|lll|}
\hline $\begin{array}{l}\text { Distribution of } \\
\text { scores }\end{array}$ & $\begin{array}{l}\text { Total no. of } \\
\text { patients }\end{array}$ & Percentage (\%) \\
\hline High & 42 & $28 \%$ \\
\hline Medium & 63 & $42 \%$ \\
\hline Low & 45 & $30 \%$ \\
\hline
\end{tabular}

The assessment of the patient's responses to the 8-item modified Morisky adherence scale showed that $42 \%$ patients were moderately adherent to anti diabetic treatment (Table 3).

\section{Factors contributing to non-adherence}

The overall prevalence of non adherence among respondents was $30 \%$. Among them $77.77 \%$ were males, $44.44 \%$ respondents belonged to age group of 4160years, $40 \%$ of illiterate, $60 \%$ employed, $51.11 \%$ of patients with smoking and alcoholic habits were not adherent to anti diabetic treatment.

Table 4: Association between patient's socio-demographic characteristics, adherent and non adherent group.

\begin{tabular}{|c|c|c|c|c|}
\hline Characteristics & No. of patients (\%) & Adherent (\%) & Non adherent (\%) & p value \\
\hline \multicolumn{5}{|l|}{ Gender } \\
\hline Male & $78(52)$ & $43(40.95)$ & $35(77.77)$ & \multirow{2}{*}{0.0001} \\
\hline Female & $72(48)$ & $62(59.04)$ & $10(22.22)$ & \\
\hline \multicolumn{5}{|l|}{ Age (years) } \\
\hline Young age (18-40) & $12(8)$ & - & $12(26.66)$ & \multirow{3}{*}{0.00001} \\
\hline Middle age (41-60) & $63(42)$ & $43(40.95)$ & $20(44.44)$ & \\
\hline Elderly age $(>60)$ & $75(50)$ & $62(59.04)$ & $13(28.88)$ & \\
\hline \multicolumn{5}{|l|}{ Educational status } \\
\hline Primary & $48(32)$ & $33(31.42)$ & $15(33.33)$ & \multirow{4}{*}{0.04527} \\
\hline Secondary & $24(16)$ & $12(11.42)$ & $12(26.66)$ & \\
\hline Tertiary & $06(4)$ & $06(5.71)$ & - & \\
\hline Illiterate & $72(48)$ & $54(51.42)$ & $18(40)$ & \\
\hline \multicolumn{5}{|l|}{ Employment status } \\
\hline Employed & $48(32)$ & $21(20)$ & $27(60)$ & \multirow{3}{*}{0.00001} \\
\hline Unemployed & $94(64)$ & $76(72.38)$ & $18(40)$ & \\
\hline Retired & $08(4)$ & $8(7.61)$ & - & \\
\hline \multicolumn{5}{|l|}{ Place of residence } \\
\hline City & $18(12)$ & $12(11.42)$ & $6(13.33)$ & \multirow{2}{*}{0.74217} \\
\hline Village & $132(88)$ & $93(88.57)$ & $39(86.66)$ & \\
\hline \multicolumn{5}{|l|}{ Social habits } \\
\hline Smoker & $16(24)$ & $10(9.52)$ & $6(13.33)$ & \multirow{4}{*}{0.00001} \\
\hline Alcoholic & $18(28)$ & $9(8.57)$ & $9(20)$ & \\
\hline Both & $30(25.33)$ & $7(6.66)$ & $23(51.11)$ & \\
\hline None & $86(57.33)$ & $79(75.2)$ & $7(15.55)$ & \\
\hline Total & 150 & 105 & 45 & \\
\hline
\end{tabular}


Factors found to be significantly associated with non adherence were age, sex, educational status, occupation and social habits (Table 4).

From Table 5, it is clear that factors such as forgetfulness, lack of information on prescribed medications, not being aware of the importance of regular medications, not visiting physician regularly and not following advice on diet are the major ones affecting non-adherence.
Among these factors, in comparison with the adherent patients, statistically significant association was observed with lack of information regarding side effects of prescribed medications, not able to visit physician regularly for consultation (due to lack of assistance, long waiting time, unhappy clinical visits),forgetfulness and not following advise on diet $(\mathrm{p}<0.05)$.

Table 5: Factors affecting both adherent and non adherent groups.

\begin{tabular}{|c|c|c|c|c|}
\hline SI. No & Factors & $\begin{array}{l}\text { Adherent group } \mathbf{n}= \\
105(\%)\end{array}$ & $\begin{array}{l}\text { Non adherent } \\
\text { group } n=45(\%)\end{array}$ & $\mathrm{p}$ value \\
\hline 1 & Lack of knowledge about prescribed medication & $37(35.23)$ & $18(40)$ & 0.5847 \\
\hline 2 & Lack of knowledge about side effects & $64(60.95)$ & $36(80)$ & 0.02334 \\
\hline 3 & Lack of assistance & $15(14.28)$ & $22(48.88)$ & 0.00001 \\
\hline 4 & Long waiting time & $20(19.04)$ & $26(57.77)$ & 0.00001 \\
\hline 5 & Unhappy clinical visits & $26(24.76)$ & $32(71.11)$ & 0.00001 \\
\hline 6 & Treatment complexity & $10(9.52)$ & $16(35.55)$ & 0.0003 \\
\hline 7 & Forgetfulness (nature of work/busy schedule) & $68(64.76)$ & $39(86.66)$ & 0.0061 \\
\hline 8 & Not following advice on exercise & 83(79.04) & $34(75.55)$ & 0.6699 \\
\hline 9 & Not following advice on diet & 40(38.09) & $26(57.77)$ & 0.0317 \\
\hline
\end{tabular}

\section{DISCUSSION}

Pharmacotherapy with dietary changes and life style modification are the major way to control diabetes and its complication. Clinical experience tells that glycemic control is not possible without patient adherence to medication. Treatment adherence is a key component for patients with diabetes.

The patient response to eight item MMAS showed that $28 \%$ patients were highly, $42 \%$ moderately and $30 \%$ poorly adherent to their antidiabetic medications. This finding is in line with study done by Khaled Heissam et al in Egypt which showed following adherence levels good adherence $26.1 \%$, fair adherence $47.9 \%$, and poor adherence $26 \% .{ }^{14}$ Contradicting to this Shobhana et al, reported very high prevalence of poor adherence $(75 \%)$ due to low socioeconomic status. ${ }^{15}$ This difference compared to our study could probably be due to availability of Free medications in our Government hospital set up and improved patients awareness and availability of better preparations.

Association of Adherence with Sociodemographic factors showed that Males predominated and were poorly adherent to treatment compared to females in the study population similar to Lertmaharit study. ${ }^{16}$ The effect of gender on rate of adherence to medication is contradictory to other studies in which men scored higher than women on self care adherence. ${ }^{9,17}$ In addition some studies could not find relationship between gender and medication adherence. ${ }^{18}$ Probable reasons for poor adherence seen in men in our study might be because of smoking, alcohol habits and other life style changes commonly seen in them. Most of our subjects were Elderly patients $(59.04 \%)$ with no formal education background $(51.4 \%)$ and they showed good adherence compare to young age group and educated subjects. Increase in awareness regarding disease and its complication might be probable reasons for increased adherence seen in elderly patients. A study done by Omar MS et al found that geriatric patients possessed high level of knowledge of their medication and disease, and their medication adherence was high $66 \% .^{19}$ In another study, high adherence was found in younger age group with $51.8 \%$ and lesser adherence was found in elderly and middle age group. ${ }^{18}$

Place of residence is an important determinant where majority of patients in our study were from rural area and were highly adherent to treatment. A similar study showed $37.14 \%$ urban patients had higher rate of adherence compared to rural area. ${ }^{17}$

In our study patients with smoking and alcohol habits have shown poor adherence, probable reasons may be forgetfulness to take medication under the influence of these social habits.

Adherence could also be affected by patient-centric, physician-dependent or health-care establishment factors. Our questionnaire addressed all the three factors and found forget fullness was one of the major patient-centric factors that were found to be higher in non-adherent patients since most of respondent were of geriatric age group. This is consistent with the findings of Aghoja et al 
study, Nigeria which concluded that non adherence among respondents occurs mostly because of forgetfulness. ${ }^{20}$

The physician-patient relationship plays a major role in keeping the patient well informed about the medications he consumes which might influence adherence. ${ }^{21}$ Patients who did not have adequate information about their drug regimens well were probably at risk of non-adherence because they had not understood how to take their drugs causing them to miss on many occasions. Many of them also revealed that they had to wait for long time to visit their physician, lack of communication between doctor and patients. Furthermore, majority were unaware of adverse effects and importance of missing medications. Therefore, there is a need to create awareness on patients on their drug regimens and to make them clearly understand the same.

Economic problems to buy medications was one of the major patient-centric factors that was found to be higher in non-adherent patients in other studies. ${ }^{11,17}$ But we did not come across this problem because the patients in the current study received free medical care and drugs.

\section{Limitations}

Use of self-reporting questionnaires, there might be tendency to overestimate adherence due to recall biases and social desirability.

\section{CONCLUSION}

Thus we conclude that patients in the area of our study were moderately adherent to their anti-diabetic medications. Various factors affecting adherence to medication were identified and evaluated.

Hereby we recommend that improving awareness about the importance of adherence in diabetic management by interventions like educating patients, medication counselling, communication between doctor and patient, simplifying drug regimen by reducing number of drugs will address these factors and improve adherence among patients.

\section{ACKNOWLEDGEMENTS}

Authors would like to thank everyone in the Department of Pharmacology and Medicine for their valuable support.

\section{Funding: No funding sources}

Conflict of interest: None declared

Ethical approval: The study was approved by the Institutional Ethics Committee

\section{REFERENCES}

1. Diabetes Action online. World Health Organization; 1999.

$$
\text { Available }
$$

http://www.who.int/diabetes/action_online/basics/en/ index.html. [Last accessed on 2016 July 20].

2. Kaveeshwar SA, Cornwall J. The current state of diabetes mellitus in India. AMJ. 2014;7(1):45-8.

3. Ciechanowski PS, Katon WJ, Russo JE, Walker EA. The patient-provider relationship: attachment theory and adherence to treatment in diabetes. American Journal of Psychiatry. 2001;158(1):29-35.

4. Garc1'a-Pe'rez LE, lvarez MA, Dilla T, Gil-Guille'n VG, Beltra'n DO. Adherence to Therapies in Patients with Type 2 Diabetes. Diabetes Ther. 2013;4:175-94.

5. Osterberg L, Blaschke T. Adherence to medication. N Engl J Med. 2005;353:487-97.

6. Gerber BS, Cho YI, Arozullah AM, Lee SY. Racial differences in medication adherence: a crosssectional study of Medicare enrollees. Am J Geriatr Pharmacother. 2010;8:136-45.

7. Walker EA, Molitch M, Kramer MK, Kahn S, Ma Y, Edelstein $\mathrm{S}$, et al. Adherence to preventive medications: predictors and outcomes in the Diabetes Prevention Program. Diabetes Care. 2006;29:19972002.

8. Sankar UV, Lipska K, Mini GK, Sarma PS, Thankappan KR. The adherence to medications in diabetic patients in rural Kerala, India. Asia Pac J Public Health; 2013.

9. Kalyango J, Owino E, Nambuya A. Non-adherence to diabetes treatment at Mulago Hospital in Uganda: prevalence and associated factors. Afr. Health Sci. 2008;8:67-73.

10. Sakthong P, Chabunthom R, Charoenvisuthiwongs R. Psychometric Properties of the Thai Version of the 8item Morisky Medication Adherence Scale in Patients with Type 2 Diabetes. The Annals of Pharmacotherapy. 2009 May;43:950-7.

11. Divya S, Nadig P. Factors contributing to nonadherence to medication among type 2 diabetes mellitus in patients attending tertiary care hospital in South India. 2015;8(2):274-76.

12. Morisky DE, Ang A, Krousel-Wood M, Ward H. Predictive validity of a medication adherence measure for hypertension control. J Clin Hypertens. 2008; 10:348-54.

13. Jin J, Sklar GE, Sen Oh VM, Chuen Li S. Factors affecting therapeutic compliance: A review from the patient's perspective. Therapeutics and Clinical Risk Management. 2008;4(1):269-86.

14. Heissam K, Abuamer Z, Dahshan N. Patterns and obstacles to oral antidiabetic medications adherence among type 2 diabetics in Ismailia, Egypt: a cross section study. Pan African Medical Journal. 2015;20:177.

15. Shobhana R, Begum R, Snehalatha C, Vijay V, Ramachandran A. Patients' adherence to diabetes treatment. J Assoc Physicians India. 1999;47(12):1173-5.

16. Lertmaharit S, Kamol-Ratankul P, Sawert H. Factors associated with compliance among tuberculosis patients in Thailand. J. Med. Assoc. Thai. 2005;88:149-56. 
17. Sajith M, Pankaj M, Pawar A, Modi A, Sumariya R. Medication adherence to antidiabetic therapy in patients with type 2 diabetes mellitus. International Journal of Pharmacy and Pharmaceutical Sciences. 2014;6(2):564-70.

18. Shams MEE, Barakat EAME. Measuring the rate of therapeutic adherence among outpatients with T2DM in Egypt. Saudi Pharmaceutical Journal. 2010;18:225-32.

19. Omar MS, San KL. Diabetes knowledge and medication adherence among geriatric patient with type 2 diabetes mellitus. Int $\mathbf{J}$ Pharm Pharm Sci. 2014;6(3):103-6.

20. Aghoja OC, Avwenaghagha HO, Ogba ER. Medication adherence and Its Correlates among
Diabetic Patients in Central Hospital, warri, Nigeria. IOSR Journal of Pharmacy. 2016;6(3):96-103.

21. Martin LR, Williams SL, Haskard KB, Dimatteo MR. The challenge of patient adherence. Ther Clin Risk Manag. 2005;1(3):189-99.

Cite this article as: Kavitha S, Nalini GK, Suresh RM, Sahana GN, Deepak P, Nagaral JV. Treatment adherence and factors contributing to non adherence among type 2 diabetes mellitus patients in a tertiary care hospital: a cross sectional study. Int J Basic Clin Pharmacol 2017;6:689-94. 